\title{
Substitution among Labour, Capital, Imported Raw Materials, and Bank Credit in Pakistan's Manufacturing ${ }^{*}$
}

\author{
ASHFAQUE H. KHAN and MOHAMMAD RAFIQ
}

\section{INTRODUCTION}

In view of its central importance to economic analysis a vast number of studies relating to the production function in its various functional forms has been undertaken during the last three decades in both the developed and the developing countries. Studies pertaining of the developing countries were primarily directed towards finding the degree of substitution between labour and capital. These efforts were ignited by the desire to explain the existence of high rates of unemployment, particularly in the urban areas. It has been argued that the near zero elasticity of substitution between labour and capital has been responsible for the existence of the high rate of unemployment. ${ }^{1}$ On the other hand, higher values for the elasticity of substitution could lead to the substitution of abundant or the faster growing factor of production (labour) for the scarce or slow growing factor (capital). Hence, a knowledge of the value of the elasticity of substitution between labour and capital in the manufacturing sector is essential for understanding the growing unemployment problem in developing countries, including Pakistan.

Numerous studies have appeared over the last several years dealing with the question of the elasticity of substitution in Pakistan's manufacturing sector using various forms of the production function as well as various sets of factor inputs. For example, Kazi et al. (1976); Battese and Malik (1987) and Zahid et al. (1992) have estimated CES production functions while Kemal (1981) and Battese and Malik (1988) have estimated both the CES and the variable elasticity of substitution (VES) production functions to determine the elasticity of substitution between labour and capital for different manufacturing industries. ${ }^{2}$ Naqvi et al. $(1983,1992)$ have estimated a $C D$ production function for the manufacturing sector as a whole.

\footnotetext{
*Owing to unavoidable circumstances, the discussant's comments on this paper have not been received

Ashfaque H. Khan and Mohammad Rafiq are, respectively, Chief of Research and Deputy Chief Programmer at the Pakistan Institute of Development Economics, Islamabad.

Authors' Note: We wish to thank Javed Ashraf for his useful comments on the earlier draft of the study. We also wish to thank Mahboob lqbal for typing several drafts of this manuscript.

ISee Laumas and Williams (1981).

${ }^{2}$ Khan and Siddiqui (1990) used both the CD and the CES production function to measure technical progress and returns to scale in manufacturing sector.
} 
Mahmood (1990) has estimated a translog production function which is more flexible than the CD or CES production functions. All these studies have used labour and capital as factor inputs. Khan $(1988,1989)$ and Chishti and Mahmood (1991) extended the input set by adding energy along with labour and capital. While Khan $(1988,1989)$ used a nested CES approach to factor substitution, Chishti and Mahmood (1991) estimated a translog production function.

Notwithstanding these achievements in the area of empirical production functions in Pakistan there appears to be enough room to make further improvements in this regard. As it is clear by now, all the studies briefly reviewed here, have used labour, capital and energy as factor inputs. At least two important factors of production have never been considered in the studies of the production function in Pakistan. In a developing country like Pakistan most manufacturing industries use imported raw materials as a factor of production. Besides imported raw materials, financial working capital is also an important variable factor of production in Pakistan. Since financial markets are not well developed, firms are heavily dependent on the domestic banking system for working capital. In these circumstances bank credit may be viewed as a complementary factor of production. Hence, it is imperative that the question of the substitution between labour and capital be considered in the presence of imported raw materials and bank credit.

The purpose of this paper is to estimate a production function for the manufacturing sector of Pakistan with an extended set of inputs, that is, labour, capital, imported raw materials and bank credit and calculate the elasticity of substitution between these factors of production as well as to measure technical progress and returns to scale in this sector.

The plan of the paper is as follows: In Section II we discuss the technique of analysis and explain the data used in this study. Section III presents the results and the final section is confined to the concluding remarks.

\section{METHODOLOGY AND DATA}

Consider a four-input production function which produces a vector of real aggregate output

$$
X=F(L, K, M, C)
$$

where $L, K, M$ and $C$ are, respectively, the labour, capital, imported raw materials and bank credit. We assume that there exists an aggregate firm which chooses the inputs level so as to minimise the cost of production of a given level of output. In other words, the aggregate firm minimises cost subject to output constraint. ${ }^{3}$

\footnotetext{
${ }^{3}$ For a detailed discussion on the advantages of following the cost minimisation approach rather than the profit maximisation approach, see Hornstein et al. (1981).
} 


$$
\begin{aligned}
& \min Z= P_{L} L+P_{K} K+P_{M} M+r_{C} C \\
& \text { st } X=F(L, K, M, C)
\end{aligned}
$$

where $P_{t}(i=L, K, M, C)$ are the factor prices.

Equation (1) represents a general production function but we need to choose an appropriate technology, i.e., the functional form for $F$. Since we have four factor inputs the $C D$ and the standard CES production functions will not be the appropriate technology because of their awkward properties of unitary and constant elasticity of substitution respectively. In such a case then the nested CES production function appears to be an appropriate choice for at least two reasons. First, because the standard CES production function with four factor inputs presumes a single elasticity of substitution between all factor pairs, i.e., $K$ is assumed to have the same substitutability with $M$ as with $L$. Creating a lower level CES functions permits differing elasticities of substitution to exist between factors. Second, the nesting CES production function expresses more information about the physical relationship between factors in the production process.

Before we proceed further it is necessary that we spell out the rule for choosing inputs to be nested at the first and subsequent levels. As suggested by Klein (1983), those factor inputs should be nested at the first level which are complementary in nature or have very low elasticity of substitution. Our initial results show that capital, imported raw materials and bank credit are complementary inputs. Hence, on the first level we begin our nesting arrangement with capital and material. On the second level, we then obtain a relationship between 'working capital' (capital-material combination) and bank credit and estimate the elasticity of substitution between these two factors. On the third level, we estimate the elasticity of substitution between 'extended working capital' (capital-material-credit combination) and labour input. The underlying assumption for the nested CES function is that the production function is strongly separable, i.e., the allocation of factors within each level is determined exclusively by the factor prices relative to that level. With this we write the three-level four input nested CES production function as

$$
\begin{gathered}
X=A\left[\theta\left(\eta\left[\delta K^{-\rho_{1}}+(1-\delta) M^{-\rho_{1}}\right]^{\rho_{2} \rho_{1}}+(1-\eta) C^{-\rho_{2}}\right)^{\rho_{3} \rho_{2}}+\right. \\
\left.(1-\theta) L^{-\rho_{3}}\right]^{-\mu \rho_{3}} \mathrm{e}^{\left(\lambda_{1}\right) \mu} \\
\cdots
\end{gathered}
$$

Where $A$ represents the total efficiency of production; $\delta, \eta, \theta$, are the distribution parameters in three level respectively, $\mu$ is the degree of homogeneity; $\rho_{i}$ $(i=1,2,3)$ represent the elasticity of substitution in three levels and are given as $\sigma_{i}$ $=1 / 1+\rho_{i} ; \lambda$ is the rate of disembodied technical progress while $K, M, C$ and $L$ are 
already defined above. ${ }^{4}$ Following the cost-minimisation approach, the outcome of optimisation at the first level is given as follows.

First Level

$$
\begin{gathered}
\ln (K M)=-\psi \sigma_{1} \ln \left(\frac{1-\delta}{\delta}\right)-\psi \sigma_{2} \ln \left(P_{K} / P_{M}\right)+ \\
(1-\psi) \ln (K M)_{-1} \\
\ldots
\end{gathered}
$$

\section{Second Level}

On the second level we measure the relationship between working capital (combination of capital and raw materials) and bank credit following their costminimisation approach. The outcome of optimisation at the second level is given as follows:

$$
\begin{aligned}
& \ln \left(X_{K M} / C\right)=-\phi \sigma_{2} \ln \quad \frac{(1-\eta)}{\eta}-\phi \sigma_{2} \ln \left(P_{K M} / P_{C}\right)+ \\
& (1-\phi) \ln \left(X_{K M} / C\right)_{-1} \quad \ldots \quad \ldots
\end{aligned}
$$

\section{Third Level}

On the third level we obtain a relationship between extended working capital (capital-material-credit combination) and labour. The objective is to measure the elasticity of substitution between these two factors. Following once again the cost minimisation approach the outcome of the optimisation at the third level is given as follows:

$$
\begin{array}{r}
\ln \left(X_{K M C} L\right)=-\beta \sigma_{3} \ln \left(\frac{1-\theta}{\theta}\right)-\beta \sigma_{3} \ln \left(P_{K M C} / P_{L}\right)+ \\
(1-\beta) \ln \left(X_{K M C} / L\right)_{-1} \quad \ldots
\end{array}
$$

Estimating Equation (6), we calculate the values for $\sigma_{3}, \rho_{3}, \theta$ and $\beta$. With the help of these estimated parameters we construct the highest level of quantum and price indices. At the end we estimate the returns to scale, efficiency parameter, and the rate of technical progress with the help of Equation (7).

$$
\operatorname{Ln} X_{m}=\ln A+\mu \ln \hat{X}_{X M C Z}+\lambda_{t} \quad \ldots \quad \ldots \quad \ldots
$$


Where $A$ is the efficiency parameter; $\mu$ measures the returns to scale and $\lambda$ is the rate of technical progress. Because intermediate inputs, $M$ and $C$, are ued on the right-hand side to explain fluctuations in $X_{m}$, Klein (1983) has suggested that the output variable must also include intermediate inputs; therefore, $X_{m}$ is truly gross output and not a value-added concept.

\section{RESULTS}

Having discussed the theory of the nested CES production function in the preceding section we now present the results corresponding to the three-level CES production function for the manufacturing sector of Pakistan. The various levels of the CES production function are estimated with the help of the ordinary least squares technique covering the time period from 1972-73 to 1990-91. The estimated results are reported in Equations (1) to (4) in Table 1.

\section{Table 1}

\section{Estimated Results of Nested CES Production Function}

\section{First Level}

$$
\begin{aligned}
\text { In }(\mathrm{K} / \mathrm{M})= & 0.45+0.23 \operatorname{In}\left(\mathrm{P}_{\mathrm{K}} / \mathrm{P}_{\mathrm{M}}\right)+0.63 \operatorname{In}(\mathrm{K} / \mathrm{M})_{-1} \\
& (1.13)(2.32)^{*} \quad(4.72)^{*} \\
\bar{R}^{2}= & 0.81 ; \mathrm{DW}=1.55 ; \mathrm{F}=44.69 ; \mathrm{SER}=0.16 \\
& \hat{\sigma}_{\mathrm{KM}}=0.62 ; \hat{\rho}=0.61 ; \hat{\delta}=0.68
\end{aligned}
$$

\section{Second Level}

$$
\begin{aligned}
& \text { In }\left(\mathrm{X}_{\mathrm{KM}} / \mathrm{C}\right)=-1.79+0.30 \operatorname{In}\left(\mathrm{P}_{\mathrm{KM}} / \mathrm{P}_{\mathrm{C}}\right)+0.728 \operatorname{In}\left(\mathrm{X}_{\mathrm{KM}} / \mathrm{C}\right)_{-1} \\
& \quad(1.18)(2.07)^{*} \\
& \bar{R}^{2}= 0.66 ; \quad \mathrm{DW}=1.36 ; \quad \mathrm{F}=20.06 ; \quad \mathrm{SER}=0.2 \\
& \hat{\sigma}_{\mathrm{KM}}=1.10 ; \hat{\rho}=0.09 ; \hat{\delta}=0.0007
\end{aligned}
$$

\section{Third Level}

$$
\begin{aligned}
\operatorname{In}\left(\mathrm{X}_{\mathrm{KMC}} / \mathrm{L}\right)= & 1.24-0.63 \operatorname{In}\left(\mathrm{P}_{\mathrm{KMC}} / \mathrm{P}_{\mathrm{L}}\right) \\
& (14.35)^{*}(2.62)^{*} \\
\bar{R}^{2}= & 0.80 ; \quad \mathrm{DW}=1.45 ; \quad \mathrm{F}=14.62 ; \quad \mathrm{SER}=0.07 \\
& \hat{\sigma}_{\mathrm{KMCL}}=-0.63 ; \hat{\rho}=-2.6 ; \hat{\delta}=0.46
\end{aligned}
$$

\section{Returns to Scale and Technical Progress}

$$
\begin{aligned}
\text { In } \mathrm{X}_{\mathrm{m}}= & 0.32+0.91 \text { In } \mathrm{X}_{\mathrm{KMCL}}+0.042 \mathrm{t} \\
& (1.42)(3.46)^{*} \\
& \bar{R}^{2}=0.98 ; \quad \mathrm{DW}=1.32 ; \quad \mathrm{F}=46.7 ; \quad \mathrm{SER}=0.056
\end{aligned}
$$


In the first level, capital and imported industrial raw materials appear to be a complementary input because the substitution elasticity between these two factors of production $\left(\hat{\sigma}_{K M}=0.62\right)$ is found to have a positive sign. For a developing country like Pakistan, imported industrial raw materials are a crucial input for the production of manufacturing goods. Thus, our strategy to nest capital and raw materials at the first level is supported by this result. The adjustment coefficient $(\psi)$ calculated as 1 minus the coefficient lagged dependent variable is $0.37(1-0.63=$ 0.37 ), which suggest that 37 percent of the discrepancies between the desired and actual levels of factor inputs are eliminated in one year. The speed of adjustment is rather slow because of the structural rigidities that prevail in Pakistan's economy.

The second level of the CES production function is estimated and the results are reported in Equation (2) in Table 1. Once again, the elasticity of substitution between working capital and bank credit $\left(\hat{\sigma}_{K M C}=1.10\right)$ is found to have a positive sign suggesting complementarity between these two inputs. In a developing country like Pakistan financial markets are generally not well developed and firms are heavily dependent on the domestic banking system for financial working capital. It is, therefore, not at all surprising that financial working capital represented by bank credit and extended working capital (combination of capital and raw materials) are found to be complementary inputs. The coefficient of adjustment $(\phi)$ in the second level of input combination is 0.27 , which suggest that only 27 percent of the discrepancies between the desired and actual levels of input are eliminated in one year. Once again, the slow adjustment is the reflection of structrural rigidities that pevails in the economy.

The third level of the CES production function is estimated and the results are reported in Equation (3) in Table 1. On the third level, the elasticity of substitution between 'extended' working capital and labour is less than unity ( $\hat{\sigma}_{K M C}$, $L=-0.63$ ), which is consistent with the CES production function. The low elasticity of substitution confirms the argument that the process of industrialisation in Pakistan brought in increasingly capital-intensive techniques of production, and there is not much scope of employment-generation in this sector. ${ }^{5}$

Finally, the results corresponding to returns to scale and technical progress are reported in Equation (4) in Table 1. The coefficient of $\left(X_{K M C L}\right)$ measures the returns to scale which is less than unity $(0.91)$, suggesting that the manufacturing sector in Pakistan exhibits decreasing returns to scale. Our finding is fairly consistent with Khan (1989); Khan and Siddiqui (1990) and Zahid et al. (1992). Equation (4) in Table 1 also reveals that the manufacturing sector did experience disembodied technical progress at the rate of 4.2 percent per annum during the period under study. This rate is slightly on the higher side compared with Khan 
(1989) and Khan and Siddiqui (1990). They, covering a time period from 1959-60 to $1986-87$ found that the manufacturing sector experienced technical progress at the rate of 3.7 percent per annum. The difference in the rate of technical progresss may be ascribed to the choice of different time periods.

\section{CONCLUDING REMARKS}

The purpose of this paper has been to estimate a production function for the manufacturing sector of Pakistan with an extended set of factor inputs that include labour, capital, industrial raw material, and bank credit and to measure the substitutability/complementarity between these factor inputs as well as to determine the returns to scale in the manufacturing sector and measure disembodied technical progress in this sector. For this purpose a three-level 'nested' CES production function is used because it permits differing elasticities of substitution between factor inputs. It is found that capital and imported raw materials are complementary inputs. It is for this reason that these two inputs were nested at the first level. On the second level, working capital (combination of capital and raw materials) and bank credit are found to be complementary inputs as well. On the third level, the elasticity of substitution between 'extended' working capital (capital-raw materials bank credit combination) and labour is found to be less than unity $\left(\hat{\sigma}_{K M C, L}=-0.63\right.$ ). The low elasticity of substitution suggests that there is not much scope for employment generation in the manufacturing sector because of its increasingly capital-intensive nature of the techniques of production.

Manufacturing industries are found to exhibit decreasing returns to scale which reflect the inefficiency in the use of factor inputs and mismanagement in this sector. This finding is consistent with other studies in this area.

It is found that the manufacturing sector did experience disembodied technical progress at the rate of 4.2 percent per annum. Finally, the adjustment between the desired and the actual levels of input in both the first and second levels of estimations are found to be slow reflecting the structural rigidities that prevails in most developing countries including Pakistan. On the third level, the adjustment between the desired and the actual levels of the ratio of 'extended' working capital to labour is found to be instantaneous.

\section{REFERENCES}

Battese, G. E., and S. J. Malik (1987) Estimation of Elasticities of Substitution for CES Production Function Using Data on Selected Manufacturing Industries in Pakistan. The Pakistan Development Review 26:2.

Battese, G. E., and S. J. Malik (1988) Estimation of Elasticities of Substitution for CES and VES Production Function Using Firm-level Data for Food Processing Industries in Pakistan. The Pakistan Development Review 27:1. 
Chishti, S., and F. Mahmood (1991) The Energy Demand in the Industrial Sector of

Pakistan. The Pakistan Development Review 30:1.

Hornstein, Z., J. Grice and A. Webb (1981) The Economics of the Labour Market.

London: Her Majesty's Stationary Office.

Kazi, S., Z. S. Khan and S. A. Khan (1976) Production Relationships in Pakistan's Manufacturing. The Pakistan Development Review 15:4.

Kemal, A. R. (1981) Substitution Elasticities in the Large-scale Manufacturing Industries of Pakistan. The Pakistan Development Review 20:1.

Khan, Ashfaque H. (1988) Factor Demand in Pakistan's Manufacturing. International Economic Journal 2:3.

Khan, Ashfaque H. (1989) The Two-level CES Production Function for the Manufacturing Sector of Pakistan. The Pakistan Development Review 28:1.

Khan, Ashfaque H., and Rizwana Siddiqui (1990) On the Measurement of Technical Progress. The International Journal of Development Planning Literature 5:1.

Khan, Ashfaque H., and M. Rafiq (1993) Substitution among Labour, Capital, Imported Raw Materials, and Bank Credit in Pakistan's Manufacturing. Paper presented at the Ninth Annual General Meeting of the Pakistan Society of Development Economists, held in Islamabad on January 7-10, 1993.

Klein, Lawrence R. (1983) International Productivity Comparison (A Review). Pro. Natl. Acad. Sci. 80: (July).

Laumas, P. S., and M. Williams (1981) The Elasticity of Substitution in India's Manufacturing Sector. Journal of Development Economics 8:3.

Mahmood, Z. (1990) The Substitutability of Emigrants and Non-migrants in the Construction Sector of Pakistan. The Pakistan Development Review 29:2.

Naqvi, Syed Nawab Haider, Ashfaque H. Khan, N. M. Khilji and A. M. Ahmed (1983) The P.I.D.E. Macro-econometric Model of Pakistan's Economy. Islamabad: Pakistan Institute of Development Economics.

Naqvi, Syed Nawab Haider, Ashfaque H. Khan and Ather M. Ahmed (1992) Macroeconomic Framework for the 8th Five Year Plan. Islamabad: Pakistan Institute of Development Economics.

Zahid, S. N., M. Akbar and S. A. Jaffry (1992) Technical Change, Efficiency, and Capital-labour Substitution in Pakistan's Large-scale Manufacturing Sector. The Pakistan Development Review 31:2. 